\title{
Preparation of O/W nano-emulsion containing nettle and fenugreek extract and cumin essential oil for evaluating antidiabetic properties
}

\author{
Sara Javadi ${ }^{1}$, Negar Motakef Kazemi ${ }^{*}$ and Raheleh Halabian ${ }^{3}$
}

\begin{abstract}
The oil-in-water (O/W) nano-emulsion (NE) is expanded to enhance the bioavailability of hydrophobic compounds. The NE can be prepared by herbal extract and essential oil as herbal medicines for antidiabetic treatment. In the present study, the O/W NE was prepared by fenugreek extract (FE), nettle extract (NE), and cumin essential oil (CEO) using tween 80 and span 80 surfactants in an ultrasonic bath, at room temperature within $18 \mathrm{~min}$. The antidiabetic property was evaluated by determining glucose absorption using cultured rat L6 myoblast cell line (L6) myotubes and insulin secretion using the cultured mouse pancreatic beta-cell (RIN-5) for NEs. The samples were investigated by dynamic light scattering (DLS) to examine the size distribution and size, zeta potential for the charge determination, scanning electron microscopy (SEM), and transmission electron microscopy (TEM) to investigate morphology and size. The rheological properties were studied by viscosity. The sample stability was evaluated at different temperatures and days by DLS and SEM analyses. The cytotoxicity of samples was explored by MTT assay for HEK293 human cell line as a specific cell line originally derived from human embryonic kidney cells at three different concentrations for three periods of time. The NEs with nanometer-size were observed with antidiabetic properties, low cytotoxicity, and suitable stability. This study provides definitive evidence for the NE as a plant medicine with antidiabetic properties. The NE can be a good candidate for biomedical applications.
\end{abstract}

Keywords: Nano-emulsion, Aqueous extract, Nettle, Fenugreek, Cumin essential oil

\section{Introduction}

Diabetes refers to a rise in glaucous blood levels because of insulin deficiency or malfunction (Modak et al., 2007). Diabetes is the fifth leading cause of death worldwide (Kazi, 2014). Nowadays, diabetes disease is on the rise globally (Mukesh \& Namita, 2013). Uncontrolled diabetes will cause an increase in the risk of some other diseases; therefore, it is vital to control and treat it (Laligani

\footnotetext{
*Correspondence: motakef@iaups.ac.ir

2 Department of Medical Nanotechnology, Faculty of Advanced Sciences and Technology, Tehran Medical Sciences, Islamic Azad University, Tehran, Iran

Full list of author information is available at the end of the article
}

et al., 2005). Diabetes has two forms called type 1 diabetes mellitus (DM) and types 2 DM (Landon et al., 2009). There are various treatments such as medication, insulin, and diet to control diabetes (Bathaie et al., 2012); however, there are disadvantages, including side effects and drug resistance in these treatments (Dey et al., 2002).

Nanotechnology has developed in different fields because of its extensive practical benefits (Ataei et al., 2020; Motakef Kazemi \& Sandalnia, 2020). Nanomaterials have potential uses due to their small size and high surface area (Jeevanandam et al., 2018; Motakef Kazemi et al., 2020). Over the past years, emulsions and nanoemulsions (NE) have attracted much interest as drug delivery systems and gene therapy (Zeinali et al., 2020) 
because of their transparency, ease of preparation, and long-term stability (Pickup et al., 2008). The emulsion method was used for preparing lipid lipid-based nanoparticles (NPs) such as solid lipid nanoparticles (SLNs), micelle such as normal micelle, polymeric NPs, and inorganic/metallic NPs (Zeinali et al., 2020). NEs can incorporate a high lipid with more homogeneous nanoparticle distributions, At the same time, SLNs can have a lower total lipid that would lead to the formation of nanoparticles with lower homogeneous particle distribution (Deli et al., 2009). The main types of NEs are oil-in-water $(\mathrm{O} / \mathrm{W})$, water-in-oil $(\mathrm{W} / \mathrm{O})$, water in oil in water $(\mathrm{W} / \mathrm{O} / \mathrm{W})$, and oil in water in oil $(\mathrm{O} / \mathrm{W} / \mathrm{O})$ (Hormann \& Zimmer, 2016). Recently, O/W NE was evaluated based on the aqueous extract and essential oil for biological applications (Feizi Langaroudi \& Motakef, 2019). NE technology is particularly suitable for encapsulating active compounds, preventing their degradation and improving their bioavailability (Haziqah Che Marzuki et al., 2019; Najafi-taher et al., 2018). NEs can be prepared via an easy method and have suitable potential applications in the food industry to deliver nutraceuticals and antimicrobial agents (Azrini Nadiha Azmi et al., 2019; Food Bioprocess Technol, 2012). NE drug systems are essential for improving the delivery and bioavailability of hydrophobic drugs over free drugs (Kumar et al., 2019). NEs have a better penetration effect of the ingredients due to the small droplet size and high surface area and low surface tension of the entire emulsion system (Bouchemal et al., 2004). The surfactant concentrations are $3-10 \%$ in NEs and $20 \%$ or higher in microemulsions (Tan et al., 2016; Dehghani et al., 2017). As a result, NEs can be good candidates for medical applications. Recently, a phospholipid complex-based NE system has been reported for oral insulin delivery (Hu et al., 2019).

So far, some nanomaterials with antidiabetic properties have been reported, including silver nanoparticles (Saratale et al., 2018), zinc oxide nanoparticles (Rehana et al., 2017), gold nanoparticles (Si et al., 2017), NE of fenugreek oil (Hassan \& Mujtaba, 2017), and NE of carvacrol (Hussein et al., 2017). Today, the use of plants plays a vital role in nanotechnology (Hajiashrafi \& Motakef, 2018). Many medicinal plants are recommended for medical applications (Kooti et al., 2015), such as psychiatric disorders (Saki et al., 2014) and analgesics (Bahmani et al., 2014). The herbs expand the diabetes treatment in various areas such as Iranian (Hasani-Ranjbar \& Mohammad Abdollahi, 2008), Indian (Saxena \& Vikram, 2004), and Chinese (Wang \& Wylie-Rosett, 2008) plants due to their ingredients. Fenugreek is one of the medicinal plants with many therapeutic applications (Basch et al., 2003), such as the effect on glycemia (Neelakantan et al., 2014), hypocholesterolemia (Al-Habori \& Raman,
1998), blood lipid, blood glucose, and platelets (Bordia et al., 1997). Also, the antidiabetic property of fenugreek has been reported in both animal models and humans (Kumar et al., 2005). Various animal models have been studied for the antidiabetic effect of fenugreek, such as rats (Kumar et al., 2005; Mowla et al., 2009) and rabbits (Abdelatif et al., 2012). The fenugreek gum's macro-and nano/submicron emulsions of fenugreek gum have been tested in terms of stability and physical properties (Kaltsa et al., 2016). Nettle is a plant with extraordinary properties (Kregie et al., 2018), such as antidiabetic property (Ahangarpour et al., 2012), control of blood pressure and glycemic (Ghalavand et al., 2017), alpha-amylase inhibition (Rahimzadeh et al., 2014), antibacterial activity (Singh et al., 2012), hyperplasia effect (Hirono et al., 1994), and anti-inflammatory properties (Obertreis et al., 1990). Cumin (Cuminum cyminum L.) is an herb with biomedical activities (Srinivasan, 2018) for different applications such as antidiabetic effect (Samani Keihan et al., 2016; Abdou Mohamed et al., 2018), antioxidant activity (Abdou Mohamed et al., 2018; Bettaieb et al., 2011), glycemic control, insulin resistance and serum inflammatory factors (Jafari et al., 2017), and aldose reductase and alpha-glucosidase inhibitor (Lee, 2005a).

Nettle extract causes severe and dose-dependent inhibition of tumor necrosis factor secretion and interleukin-6 (Teucher et al., 1996). Also, caffeic-malic, which is the main phenolic component of nettle, inhibits the synthesis of cyclooxygenases in a dose-dependent manner, thus inhibiting the production of cytokines, which can lower blood sugar (Obertreis et al., 1990). Glycosylated hemoglobin is an indicator of serum protein glycosylation status in patients with diabetes. Due to its structural similarity to glucose, vitamin $\mathrm{C}$ can reduce the rate of hemoglobin glycosylation in patients with type 2 diabetes by competing with glucose (Gomez-Perez et al., 2010). Vitamin $\mathrm{C}$ is abundant in the leaves of the nettle plant. The presence of large amounts of vitamin $C$ in nettle leaves can be one of the causes of decreased hemoglobin glycosylation in the intervention group. However, heat reduces the amount of vitamin $C$. The amount of vitamin $\mathrm{C}$ remaining in the extract and other compounds in nettle and their synergistic effects could effectively reduce the percentage of HbA1C (Tarighat Esfanjani et al., 2012). In addition, nettle contains large amounts of flavonoids (Mehri et al., 2011). Among them, quercetin from the family of polyphenols is more than other flavonoids in nettle leaves. With its antioxidant properties, Quercetin alters cellular function, and flavonoids can improve blood sugar indices (Song et al., 2005). Hydroalcoholic extract of nettle, through its antioxidant properties and inhibition of free radicals, regenerates pancreatic beta cells and thus reduces blood sugar levels in the rat (Golalipour 
et al., 2006). Polyphenols typically significantly reduced fasting glucose and glycosylated hemoglobin after 45 days in diabetic rats, while not affecting glucose indices in healthy rats (Golalipour \& Khori, 2007a). Tannins and carotenoids are also considered constituents of nettle (Kamalakkannan \& Prince, 2006). Cumin fruit contains large amounts of antioxidants. Ascorbic acid, niacin, copper, and magnesium in cumin seeds have anti-diabetic effects (Talpur et al., 2005). It also delays and reduces the process of hyperlipidemia (Lee, 2005b). Numerous pharmacological studies and clinical trials have been performed on the hypoglycemic and cholesterol-lowering effects of fenugreek seeds and their various extracts. In most of these studies, the above effects have been confirmed. In addition to the physical effect of fibrous compounds, mucilage, and saponins present in the grain, which cause delay or incomplete absorption and lack of absorption of carbohydrates and cholesterol, some other compounds in the plant have been known as the leading causes of these effects. The amino acid 4-hydroxy isoleucine, the primary amino acid in fenugreek seeds, is one of the main blood sugar-lowering compounds in the plant that stimulates insulin release from the pancreas. Trigonelline, nicotinic acid, and coumarin compounds have also been reported in some studies to have an antidiabetic effect on the plant. The critical point about the antidiabetic effects of this plant is that after consuming fenugreek seeds, the clinical symptoms of diabetes, especially polyuria, polydipsia, weakness and lethargy, and weight loss, are significantly improved. Fenugreek also decreased low-density and very-low-density lipoprotein and increased high-density lipoprotein in people with type 2 diabetes and alloxan-induced diabetic rats. The compound of saponin in fenugreek has been introduced as an anti-inflammatory, antimicrobial, and antiviral agent of the plant (Leung \& Foster, 1996; Wichtl \& Bisset, 1994; Barnes et al., 1996; Duke, 2002; Al-Habori \& Raman, 1985). In this study, we prepared new nanoemulsions for diabetes treatment duo to the studied and proven properties of these plants in improving diabetes and the synergy of these properties, which has not been done already. This article objective was to prepare $\mathrm{O} / \mathrm{W}$ $\mathrm{NE}$ containing nettle and fenugreek extract and cumin essential oil (CEO) for antidiabetic properties and investigating cytotoxicity on Human fetal kidney cell (HEK293) cell line. This study provides important new information about NEs based on essential oils and aqueous extract for biomedical applications.

\section{Materials and methods Materials}

All chemicals were of analytical grade. Ultrapure water was used for preparing all reagents solutions. Tween 80 and span 80 were purchased from Merck Millipore (Germany) as surfactants.

Fenugreek and nettle aqueous extracts were prepared from Adonis Gol Daro (Iran). Fenugreek and nettle in Iran were collected from Kashan in July and from Mazandaran in May, respectively. The samples were washed thoroughly with double distilled water to remove the dust particles. They were then confirmed by herbarium PMP-1741 for fenugreek (Trigonella foenum-graecum) and PMP-1379 for nettle (Urtica dioica) Tehran University. Finally, the samples were cut into pieces and dried in the presence of sunlight. For preparing the extract, $500 \mathrm{~g}$ of the samples was immersed in the $4 \mathrm{~L}$ of DD water and boiled to prepare $1 \mathrm{~L}$ of extract. CEO was purchased from Barij Essence (Iran) with FCL63-03 code and I951584 sample serial number.

HEK293 was prepared from the Iranian Institute of Pasteur (Iran) to investigate cytotoxicity assay. Mouse pancreatic beta-cell (RIN-5) and rat L6 myoblast cell line (L6) were obtained from the Iranian Biological Resource Center (Iran) and the Iranian Institute of Pasteur (Iran) for diabetic tests, respectively. The culture media (RPMI 1640 and DMEM/F12) were purchased from INOCLON company (Iran).

\section{Methods}

\section{Preparation of nano-emulsion}

In the preparation of mint nano-emulsion, tween 80 and span 80 have been used as surfactants (Feizi Langaroudi \& Motakef, 2019). Also, in another study, span 80 was used to prepare saffron nano-emulsion (Karimi \& Motakef, 2021). These materials were selected as this study's surfactants, due to the low toxicity and pharmacy uses of these surfactants (Mc Clements, 2013). To prepare netthe nano-emulsion, tween 80 and span 80 were used separately, and it was observed that span 80 did not have good immediate stability, but tween 80 was apparently stable. The same thing was repeated for fenugreek nano-emulsion, and it turned out that tween 80 did not have good temporary stability, but span 80 had good stability. Therefore, tween 80 was selected for nettle nano-emulsion and span 80 for fenugreek nano-emulsion of preparation.

According to the percentages mentioned in the research for mint nano-emulsion (Feizi Langaroudi \& Motakef, 2019), nano-emulsions were prepared with $3 \%$ of different materials, and then the DLS evaluation and the sample appearance showed a sample with a medium percentage containing $95 \%$ of the extract, which is desirable and was used as a formulation for the preparation of nano-emulsions. According to the previous report for the preparation of mint nano-emulsion, the percentage of NE components is presented in Table 1 (Feizi Langaroudi \& Motakef, 2019). Based on the previous article 
Table 1 The percentage of NE components

\begin{tabular}{llll}
\hline Sample & $\begin{array}{l}\text { Essential oil } \\
\text { (w/w\%) }\end{array}$ & $\begin{array}{l}\text { Aqueous extract } \\
\text { (w/w\%) }\end{array}$ & Surfactant (w/w\%) \\
\hline I & 4 & 94 & $2($ Span 80) \\
II & 4 & 94 & $2($ Tween 80) \\
III & 2 & 96 & $2($ Span 80) \\
IV & 2 & 96 & $2($ Tween 80) \\
V & 4 & 95 & 1 (Span 80) \\
VI & 4 & 95 & 1 (Tween 80) \\
\hline
\end{tabular}

and another study on saffron nano-emulsion that used a homogenizer at room temperature (Karimi \& Motakef, 2021), when we used a homogenizer to prepare a mint nano-emulsion, we first used a homogenizer. However, we used an ultrasonic bath and an ultrasonic probe due to the lack of easy access to the homogenizer and compared the results. The results show that the particle size in the method of using a homogenizer for the preparation of nettle nano-emulsion is $22 \mathrm{~nm}$; in the method of using an ultrasonic bath, it is $23 \mathrm{~nm}$ (Fig. 1). In the end, there was no significant difference between the homogenizer and ultrasonic bath results, and we were able to use the ultrasonic bath (Parsonic7500s, Iran) as an alternative method.

Also, because in the previous article, a homogenizer was used for $30 \mathrm{~min}$, and an ultrasonic bath had a maximum of $18 \mathrm{~min}$ at first use, it remained for $18 \mathrm{~min}$, and a good result was obtained, so the method based on the ultrasonic bath was selected for $18 \mathrm{~min}$. Fenugreek nanoemulsion (FN) was prepared from a mixture of CEO, surfactant, and fenugreek aqueous extract (FAE) by an ultrasonic bath for $18 \mathrm{~min}$ in the presence of tween 80 and span 80 surfactants. Nettle nano-emulsion (NN) was prepared exactly similar to $\mathrm{FN}$, but in the presence of nettle aqueous extract (NAE). The CEO and surfactant were mixed on a stirrer, and then the aqueous extract was added slowly.

The transport and consumption of soluble medicines by the patient are a little complicated. On the other hand, the advantages of freeze-drying include no oxidation of the material, no new composition, reduced adhesion of materials, uniformity of particle size, and increased shelf life, especially in the case of drugs (Wang et al., 2017). Consequently, we used the freeze-drying method to dry the samples to make the samples into solid powder.

To perform the freeze-drying process, $100 \mathrm{ccs}$ of each sample was prepared separately, poured into $10 \mathrm{~cm}$ plates, and placed in the freezer for 1 day. Then, we took the samples out of the freezer, covered them with foil, and made a few holes on the foil to let the solvent out. The samples were placed in a freeze dryer for $24 \mathrm{~h}$. After $24 \mathrm{~h}$, as the samples still contained solvent, they were placed in the freeze dryer for another $24 \mathrm{~h}$. After $24 \mathrm{~h}$, the sample was placed in the machine for a total of $48 \mathrm{~h}$, and the fenugreek sample was wholly dried, and the nettle sample had a little water. To dry, we covered it with a few holes covered with foil and put it in the cupboard to dry.

\section{Evaluating of nano-emulsion}

Dynamic light scattering was reported in size and size distribution (ZEN314, England). To obtain DLS, first, pour the sample into the tube for the device, and then place it in it. After adjusting the solvent (FAE and NAE for each sample) and soluble (CEO) parameters, wait for $300 \mathrm{~s}$ and obtain the corresponding diagram. This method was repeated three times. There is no need to dilute the sample. To study the particle size distribution after freeze-drying, first, the size of a spatula tip of each sample was poured into $5 \mathrm{cc}$ of distilled water and placed in an ultrasonic bath for $10 \mathrm{~min}$, and then DLS was taken from the solution. Scanning electron microscope was employed to observe the morphology and size (KYKY EM3200, China). Transmission electron microscopy was also used to observe the morphology and size of samples (Zeiss-EM10C-100 KV, Germany). The rheological properties were studied by examining viscosity based on spindle speed for samples using Reologica Instruments $\mathrm{AB}$ (Lund, Sweden). The NEs were allowed to equilibrate for $72 \mathrm{~h}$ before evaluating their rheological properties. Rheology of flow science and deformation of currents describes the interaction between forces, deformation, and time. The setting of the rheometer is based on the formation of the structure in the time period and at the appropriate temperature based on previous study (Feizi Langaroudi \& Motakef, 2019). The NEs were placed under minimum stress of $0.05 \mathrm{~Pa}$ and maximum stress of $550 \mathrm{~Pa}$ and $600 \mathrm{~Pa}$. Rheograms were obtained automatically in triplicate while gradually increasing shear stress to the specified maximum stress.

\section{In vitro studies}

In this study, two types of cells were used: RIN- 5 and the L6. L6 cells were purchased from the Pasteur Institute of Iran, and RIN-5 cells were purchased from the Iranian Biological Resource Center. The specific culture medium for the L6 cell line was DMEM $+2 \mathrm{mM}$ glutamine $10 \%$ fetal bovine serum (FBS), and the specific culture medium for the RIN-5 cell line was RPMI $1640+10 \%$ FBS $+2 \mathrm{mML}$-glutamine. Each cell was placed in its culture medium, where $1 \%$ antibiotic $(100 \mathrm{IU} / \mathrm{ml}$ penicillin and $100 \mu \mathrm{g} / \mathrm{ml}$ streptomycin) was added to its culture medium. Then, it was maintained in a humidified incubator with $5 \% \mathrm{CO}_{2}$ at $37^{\circ} \mathrm{C}$. The cells were cultured in a flask with the required density and incubated for a while before the test. 

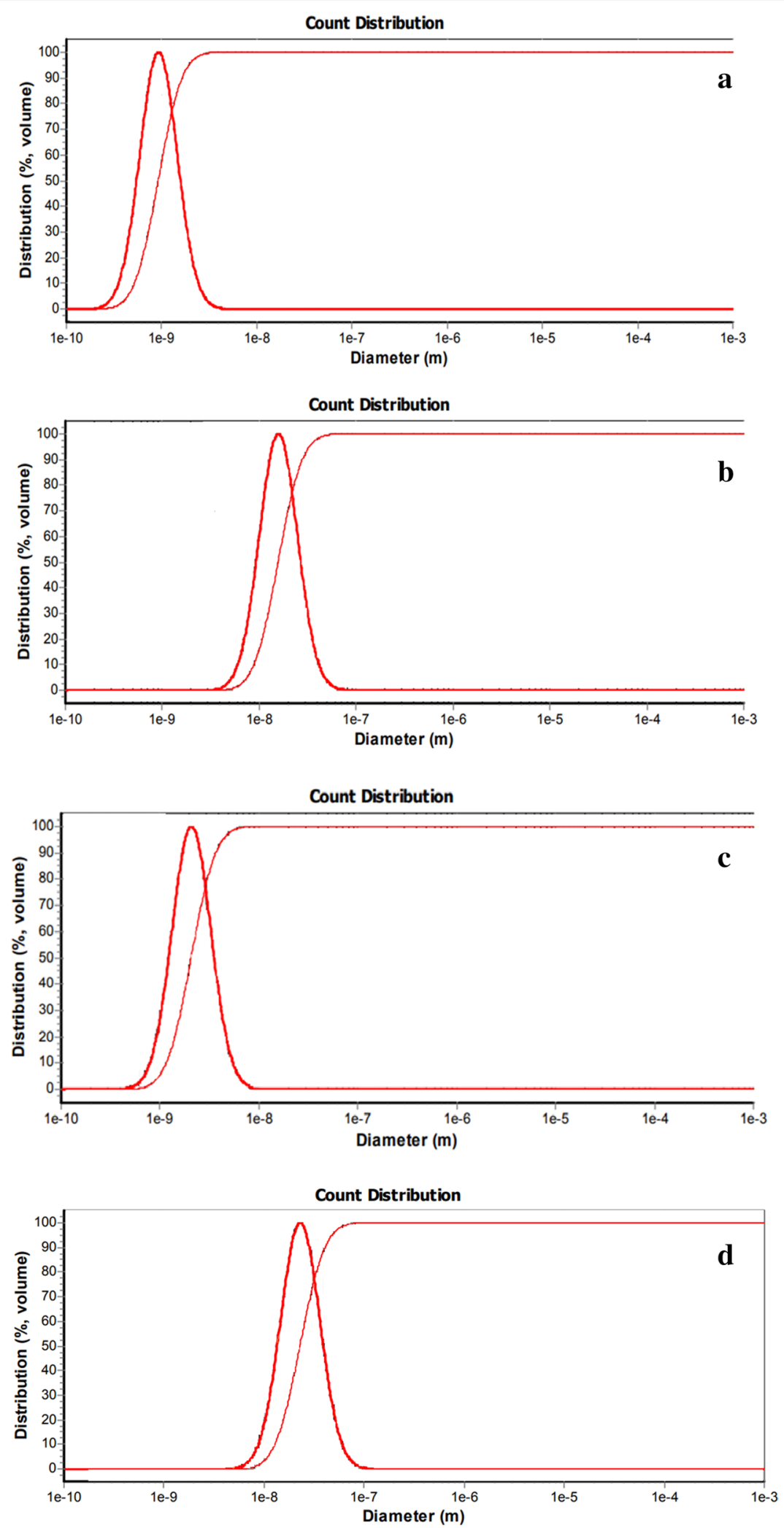

Fig. 1 DLS diagram of NN with different preparation methods. a 30 min homogenizer. b 15 min homogenizer. c 15 min ultrasonic probe. d 18 min ultrasonic bath 
The cytotoxicity was investigated by HEK293 for MTT assay at three different concentrations for 1,3 , and 5 days. The cell line was purchased from the Pasteur Institute of Iran. The specific culture medium for this cell line is RPMI 1640+10\% FBS. HEK293 cells were used to carry out a cytotoxic test, where we cultured 5000 cells in each of the 96-well plates with $1 \mathrm{ml}$ of a specific culture medium. Then, the cells were incubated for $24 \mathrm{~h}$ at $37^{\circ} \mathrm{C}$ and $5 \% \mathrm{CO}_{2}$. After incubation, the media was changed with a new medium that contains a substance that we want to use in different concentrations $(0,0.5,0.25$, $0.12 \mathrm{mg} / \mathrm{ml}$ ) for toxicity. Next, it was incubated for 24,72 , and $120 \mathrm{~h}$. After this period, the supernatant medium was discarded, and adherent cells were washed by phosphate buffer solution (PBS). We added about $20 \mu \mathrm{L}$ of MTT solution ( $5 \mathrm{mg} / \mathrm{mL}$ MTT bromide in PBS) and incubated it for $4 \mathrm{~h}$ at $37^{\circ} \mathrm{C}$. The medium was removed, and the MTT formazan crystals formed by living cells were dissolved in $100 \mu \mathrm{L}$ of dimethyl sulfoxide. The absorbance was measured at $595 \mathrm{~nm}$, and the number of living cells was calculated with the standard curve. This test was then performed for RIN-5 and L6 cells at an optimal concentration obtained from the previous tests, for different samples, for $24 \mathrm{~h}$.

The antidiabetic property was evaluated by two methods, including the amount of glucose absorbed by the L6 cells and the amount of insulin released from the RIN-5 cells. For evaluating the glucose absorbed amount, the L6 cells were transferred in 24-well plates at $5 \times 10^{4}$ cells in each well with $1 \mathrm{ml}$ of their medium culture. Then, we added Krebs-Henseleit buffer ( $\mathrm{pH} 7.4,0.141 \mathrm{~g} / \mathrm{L}$ of $\mathrm{MgSO}_{4}, 0.16 \mathrm{~g} / \mathrm{L}$ of $\mathrm{KH}_{2} \mathrm{PO}_{4}, 0.35 \mathrm{~g} / \mathrm{L}$ of $\mathrm{KCl}, 6.9 \mathrm{~g} / \mathrm{L}$ of $\mathrm{NaCl}, 0.373 \mathrm{~g} / \mathrm{L}$ of $\mathrm{CaCl}_{22} \mathrm{H}_{2} \mathrm{O}$, and $2.1 \mathrm{~g} / \mathrm{L}$ of $\mathrm{NaHCO}_{3}$ ) containing $0.1 \%$ bovine serum albumin, $2 \mathrm{mM}$ sodium pyruvate, and $10 \mathrm{mM}$ Hepes (KHH buffer). Thereafter, two modes with low glucose and high glucose cultures were used for testing glucose intake in each environment: (1) without adding any of the samples, (2) with NE, (3) with aqueous extracts, and (4) with essential oil and incubated for $4 \mathrm{~h}$. Then, we measured the concentration of glucose in the environment, reduced the initial concentration of glucose in the environment, and obtained the amount of glucose absorbed by the cell.

For evaluating the amount of released insulin, the RIN-5 pancreatic cells were transferred to 24-well plates at $2 \times 10^{5}$ cells in each well with $1 \mathrm{ml}$ of the medium culture, with the cells cultured at $37{ }^{\circ} \mathrm{C}$ and $5 \% \mathrm{CO}_{2}$ incubator. After $24 \mathrm{~h}$, the cell culture medium was replaced, and the cells were placed adjacent to a new culture medium containing glucose concentration (12.5 mM glucose). Next, the cells were incubated for $3 \mathrm{~h}$. After this time, the adjacent by the appropriate concentrations of cell toxicity test results from each NE, extracts, and essential oils with $1 \%$ FBS. Then, they were incubated for $6 \mathrm{~h}$. After this period, with a specific ELISA kit (Insulin ELISA kit, Ab100578, Abcam, Cambridge, UK), cell insulin levels were measured, and the level of insulin secreted for each sample was compared with the level of control insulin secretion (without any sample).

\section{Results and discussion}

\section{Dynamic light scattering}

DLS evaluated particle size and size distribution of the NE (Fig. 1). The optimum sample had a single-peak with a narrow distribution on nanometer-scale including $\mathrm{CEO}$ (4\% w/w), FAE (95\% w/w), and span $80(1 \% \mathrm{w} / \mathrm{w})$ for FN and CEO $(4 \% \mathrm{w} / \mathrm{w}), \operatorname{NAE}(95 \% \mathrm{w} / \mathrm{w})$, and tween $80(1 \%$ $\mathrm{w} / \mathrm{w})$ for NN. The mean particle diameter of optimum NE was observed at $23 \mathrm{~nm}$ for NN and $86 \mathrm{~nm}$ for FN (Fig. 1a, b). The results of the optimal percentage were similar to the previous study for different herbal nano-emulsion (Feizi Langaroudi \& Motakef, 2019).

Dynamic light scattering was used to evaluate NE stability after various times 30 and 90 days included, at different temperature conditions, including $24,4,-4$, and $-20^{\circ} \mathrm{C}$. The stability of the samples was confirmed by changing the time and temperature using a DLS diagram. The mean particle diameter was $37,50,80$, and $102 \mathrm{~nm}$ respectively (Fig. 1c-f) for $\mathrm{NN}$ and 97, 98, 105, and $127 \mathrm{~nm}$ (Fig. $1 \mathrm{~g}-\mathrm{j}$ ) for $\mathrm{FN}$ at $24,4,-4$, and $-20^{\circ} \mathrm{C}$ respectively after 30 days. Based on the results, the samples' size did not change considerably; in other words, they were stable at different temperatures. The DLS results of the optimum sample and the 30-day stability at different temperatures are summarized in Table 2 . The slight reduction of particle size may be due to the intense shaking of the solution and the decrease of hydrodynamic radius before DLS analysis, while the slight increase of particle size was because of the growing phenomenon. The optimum temperature was selected based on particle size at $24{ }^{\circ} \mathrm{C}$ for subsequent experiments. These results have been reported for the first time.

The stability was studied for nettle and fenugreek NEs by DLS analysis at $24^{\circ} \mathrm{C}$ after 90 days. DLS results showed a single-peak and a narrow distribution diagram with a size of $135 \mathrm{~nm}$ for $\mathrm{NN}$ and $115 \mathrm{~nm}$ for FN, which confirmed a partial change of size (Fig. $2 \mathrm{k}, \mathrm{l}$ ). The results were comparable to the natural anti-proliferative agent loaded self-micro emulsifying nanoparticles for potential therapy in oral squamous carcinoma (PatilAmol et al., 2019).

The effect of the freeze-drying process was investigated on the size of nettle and fenugreek NEs via DLS analysis for 2 days. DLS results showed a single-peak and a narrow distribution diagram with about $115 \mathrm{~nm}$ for $\mathrm{NN}$ and $105 \mathrm{~nm}$ for FN (Fig. 2m, n). Accordingly, a minor 
Table 2 DLS results of the optimum sample and the 30-day stability at different temperatures

\begin{tabular}{llll}
\hline Sample & Sampling time and temperature & Number of peaks & $\begin{array}{c}\text { Particle } \\
\text { size } \\
(\mathbf{n m})\end{array}$ \\
\hline FN & Primary sample & 1 & 86.3 \\
FN & After a month at a temperature of $22-24^{\circ} \mathrm{C}$ & 1 & 98.7 \\
FN & After a month at a temperature of $3-4^{\circ} \mathrm{C}$ & 1 & 97.9 \\
FN & After a month at a temperature of -3 to $-4^{\circ} \mathrm{C}$ & 1 & 105 \\
FN & After a month at a temperature of $-20^{\circ} \mathrm{C}$ & 1 & 127 \\
NN & Primary sample & 1 & 23 \\
NN & After a month at a temperature of $22-24^{\circ} \mathrm{C}$ & 1 & 37.3 \\
NN & After a month at a temperature of $3-4^{\circ} \mathrm{C}$ & 1 & 43.1 \\
NN & After a month at a temperature of -3 to $-4{ }^{\circ} \mathrm{C}$ & 1 & 79.9 \\
NN & After a month at a temperature of $-20^{\circ} \mathrm{C}$ & 102 \\
\hline
\end{tabular}

reduction in size results from a decline in the hydrodynamic radius.

Zeta potential was used to determine the surface charge of NE. Based on the results, the zeta potential was $-3.85 \mathrm{mv}$ for NN and $+7.89 \mathrm{mv}$ for FN (Fig. 3).

The more stable sample had a higher value (positive or negative) of zeta potential. The zeta potential result was according to a previous study with different nano-emulsion (Sharifi et al., 2021). The results showed low stability of the samples, but this could be due to the sedimentation of the samples, which is reversible and returns to its previous state by simply stirring or shaking the container. As shown in Fig. 4 for $\mathrm{NN}$ and Fig. 5 for FN, the sample was divided into two phases before shaking and returned to the previous state after shaking. Evaluations such as DLS and anti-diabetic properties were performed after shaking the sample.

\section{Scanning electron microscopy}

The SEM images showed NEs with spherical morphology (Fig. 6). According to the results, the particle size was estimated for $\mathrm{NN}$ about $90 \mathrm{~nm}$ and $\mathrm{FN}$ about $75 \mathrm{~nm}$ and confirmed DLS results (Fig. 6a, b). The result was according to a previous study with Mint nano-emulsion (Feizi Langaroudi \& Motakef, 2019).

Scanning electron microscopy was employed to evaluate NE stability after various times, including 30 and 90 days, at different temperature conditions, including $24,4,-4$, and $-20^{\circ} \mathrm{C}$. SEM results were investigated for NEs at $24^{\circ} \mathrm{C}$ after 30 days (Fig. 6c, d), which confirmed the preservation of particles' size and morphology. The particle size growth was observed for netthe and fenugreek NEs after 90 days at $24^{\circ} \mathrm{C}$ (Fig. 6e, f). Unlike DLS results, SEM results showed instability of the sample after 90 days, which could be due to a change in the SEM device or the operator of the device and its lack of knowledge in drying the sample. The SEM results revealed spherical nanoparticle morphology for nettle and fenugreek NEs after the freeze-drying process for two days (Fig. $6 \mathrm{~g}$, h), which confirmed the size results of DLS. SEM images confirmed the stability of the samples with time and temperature change. The results have been studied for the first time.

\section{Transition electron microscopy}

The TEM results are shown for fenugreek and nettle NEs (Fig. 7) and conformed to the SEM and DLS results. The samples were observed with spherical morphologies with $34.5 \mathrm{~nm}$ particle size for $\mathrm{NN}$ and $58.3 \mathrm{~nm}$ particle size for FN, which confirm nano-size range of the emulsions. The morphology result was according to the TEM of a previous study for different nano-emulsion (Kumari et al., 2018).

\section{Rheological properties}

Rheology is the study of the flow of matter that deals with the deformation and flow of materials (Mehrnia et al., 2017). Rheological analysis plays a very important role in the design of release systems (Jaworska et al., 2015). Rheology tests were performed to determine viscosity of NEs at different shear rates (until $1000 \mathrm{~s}^{-1}$ ). According to the result, the viscosity of $\mathrm{FN}$ was higher than that of $\mathrm{NN}$ at the same shear rate $\left(200 \mathrm{~s}^{-1}\right)$; for example, the viscosity was 20 and 19 (Pas.s) at the same shear rate of $200 \mathrm{~s}^{-1}$ for fenugreek and nettle NEs respectively, which can be due to smaller size and a more significant number of particles in a constant volume. Knowledge of nano-emulsion rheology is essential and can indicate the shelf life of these products. The interactions between molecules, such as van der Waals, electrostatic or hydrophobic forces, have a large effect on the rheological properties. If the emulsion is a system with a high degree of dispersion, the 

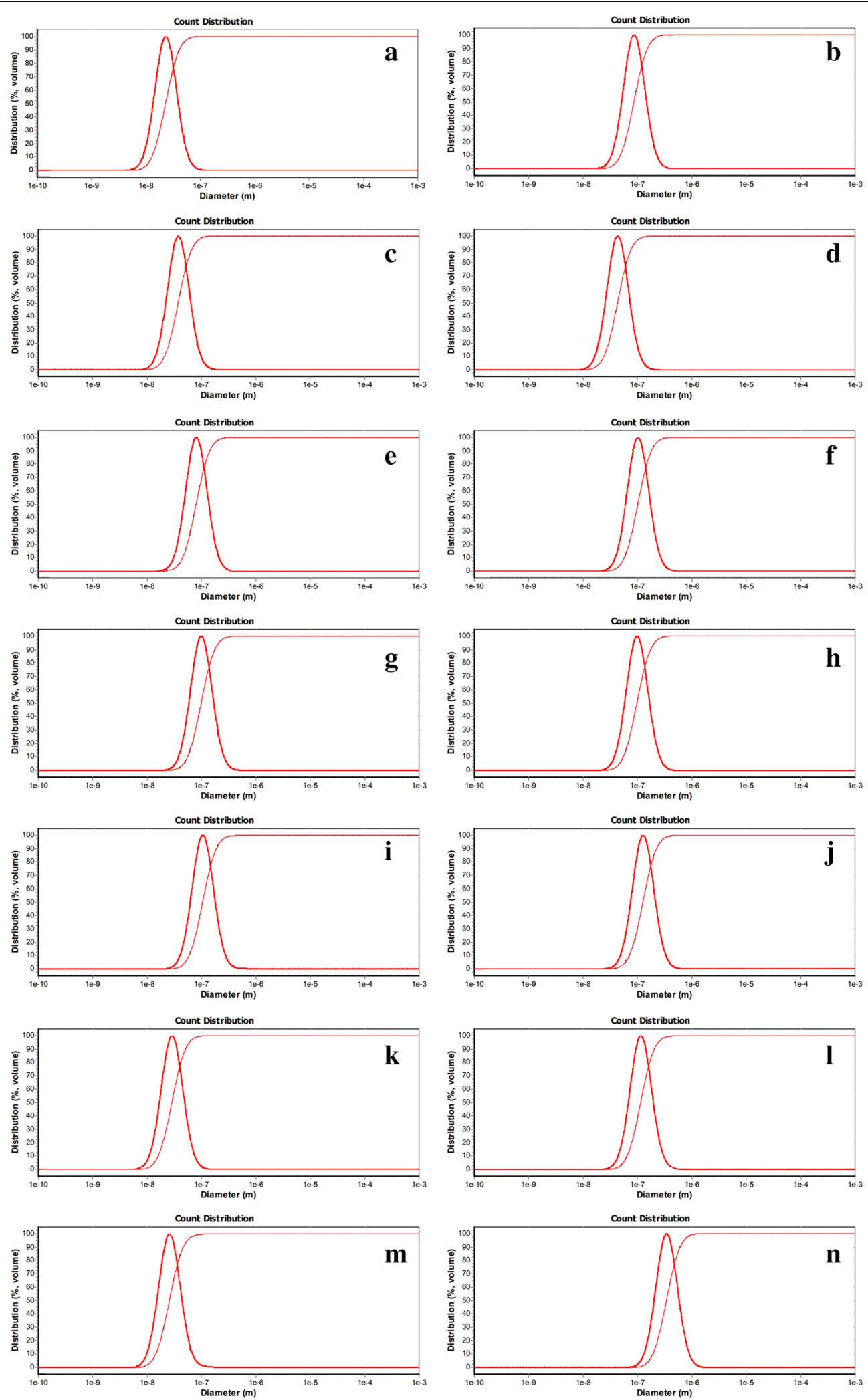

Fig. 2 DLS diagram of a NN in the optimum percentage, $\mathbf{b} F N$ in the optimum percentage, $\mathbf{c ~ N N}$ after 30 days at $24^{\circ} \mathrm{C}, \mathbf{d} N N$ after 30 days at $4^{\circ} \mathrm{C}$, e NN after 30 days at $-4^{\circ} \mathrm{C}, \mathbf{f ~ N N}$ after 30 days at $-20^{\circ} \mathrm{C}, \mathbf{g} \mathrm{FN}$ after 30 days at $24^{\circ} \mathrm{C}, \mathbf{h} \mathrm{FN}$ after 30 days at $4^{\circ} \mathrm{C}, \mathbf{i} \mathrm{FN}$ after 30 days at $-4^{\circ} \mathrm{C}, \mathbf{j}$ FN after 30 days at $-20^{\circ} \mathrm{C}, \mathbf{k} N N$ after 90 days at $24^{\circ} \mathrm{C}, \mathbf{I} N$ NE after 90 days at $24^{\circ} \mathrm{C}, \mathbf{m}$ NN after freeze-drying, and $\mathbf{n} \mathrm{FN}$ after freeze-drying 
a Zeta Potential Distribution

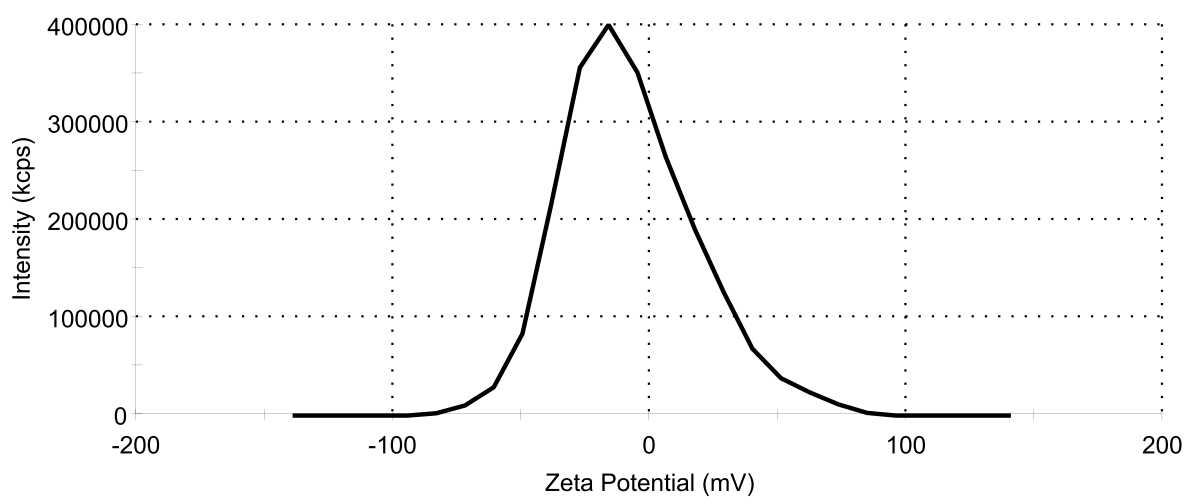

b Zeta Potential Distribution

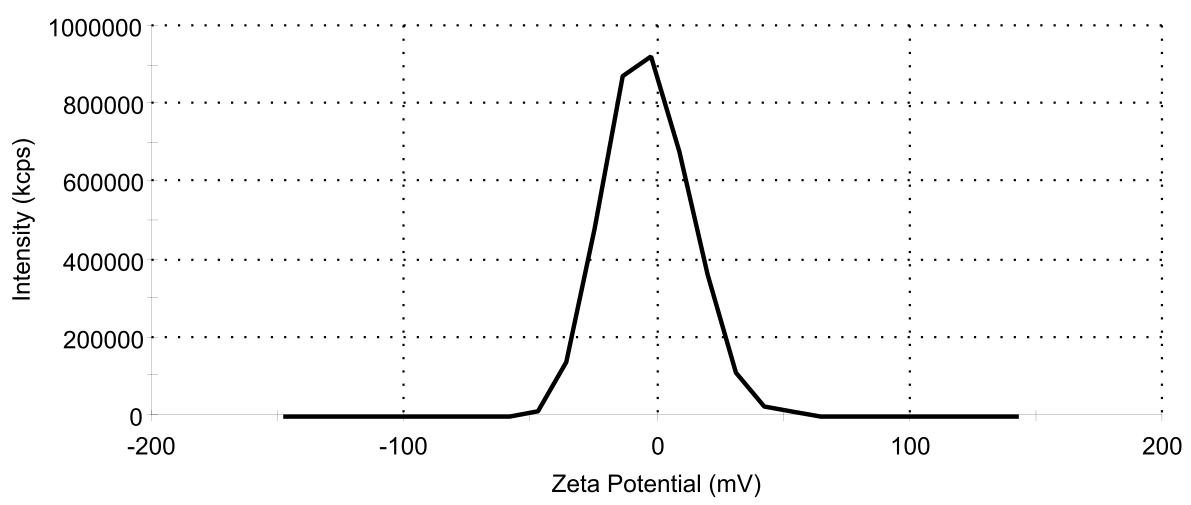

Fig. 3 Zeta potential diagram of a nettle and $\mathbf{b}$ fenugreek NEs

interaction between the particles is weak. However, if the number of droplets increases, the interaction between them becomes stronger and at the same time the viscosity of the whole system increases (Jaworska et al., 2015). According to the diagrams (Fig. 8), the viscosity of fenugreek nano-emulsion was higher at the same cutting speed, which indicates less stability of this. In total, both samples showed relatively high viscosity, indicating their low stability. The result concurred with a previous study (Feizi Langaroudi \& Motakef, 2019). The rheological properties of NEs can be adjusted by controlling the fraction of the dispersed phase volume and the type of components (Madar \& Shomer, 1990).

\section{MTT assay}

The cytotoxicity of samples was investigated by MTT assay at different concentrations $(0,0.12,0.25$, and $0.5 \mathrm{mg} / \mathrm{ml}$ ) by HEK239 human cell line for three periods of time (1, 3, and 5days) as well as RIN-5 and L6 cells for 1 day. Figure 9 displays cytotoxicity results of the NN, FN, NAE, FAE, and CEO with different concentrations and control concentration (zero) by HEK239 human cell line. After one day, the concentrations of 0.25 and $0.12 \mathrm{mg} / \mathrm{ml}$ showed the appropriate viability of cell and the lowest cell death, but the concentration of $0.5 \mathrm{mg} /$ $\mathrm{ml}$ was observed to increase cell death rate. After 3 days, the results revealed high cell death for the concentration of $0.5 \mathrm{mg} / \mathrm{ml}$ and low cell death for two concentrations of 0.25 and $0.12 \mathrm{mg} / \mathrm{ml}$. There was no significant difference between the two concentrations of 0.12 and $0.25 \mathrm{mg} / \mathrm{ml}$. After 5 days, the results indicated high cell death for a concentration of $0.5 \mathrm{mg} / \mathrm{ml}$ and low cell death and approximately equal for two concentrations of 0.25 and $0.12 \mathrm{mg} / \mathrm{ml}$. Based on the result, concentration and time were two influential factors on cytotoxicity, and the increase of concentration and time caused the higher cytotoxicity. The result was in line with a previous study (Saratale et al., 2018). Cytotoxicity results indicated that two concentrations of 0.25 and $0.12 \mathrm{mg} / \mathrm{ml}$ were appropriate. Due to the low difference in the results of these two concentrations, the highest possible concentration for subsequent tests was selected $0.25 \mathrm{mg} / \mathrm{ml}$.

The cytotoxicity of samples for a concentration of $0.25 \mathrm{mg} / \mathrm{ml}$ was investigated by RIN-5 and L6 cells for 

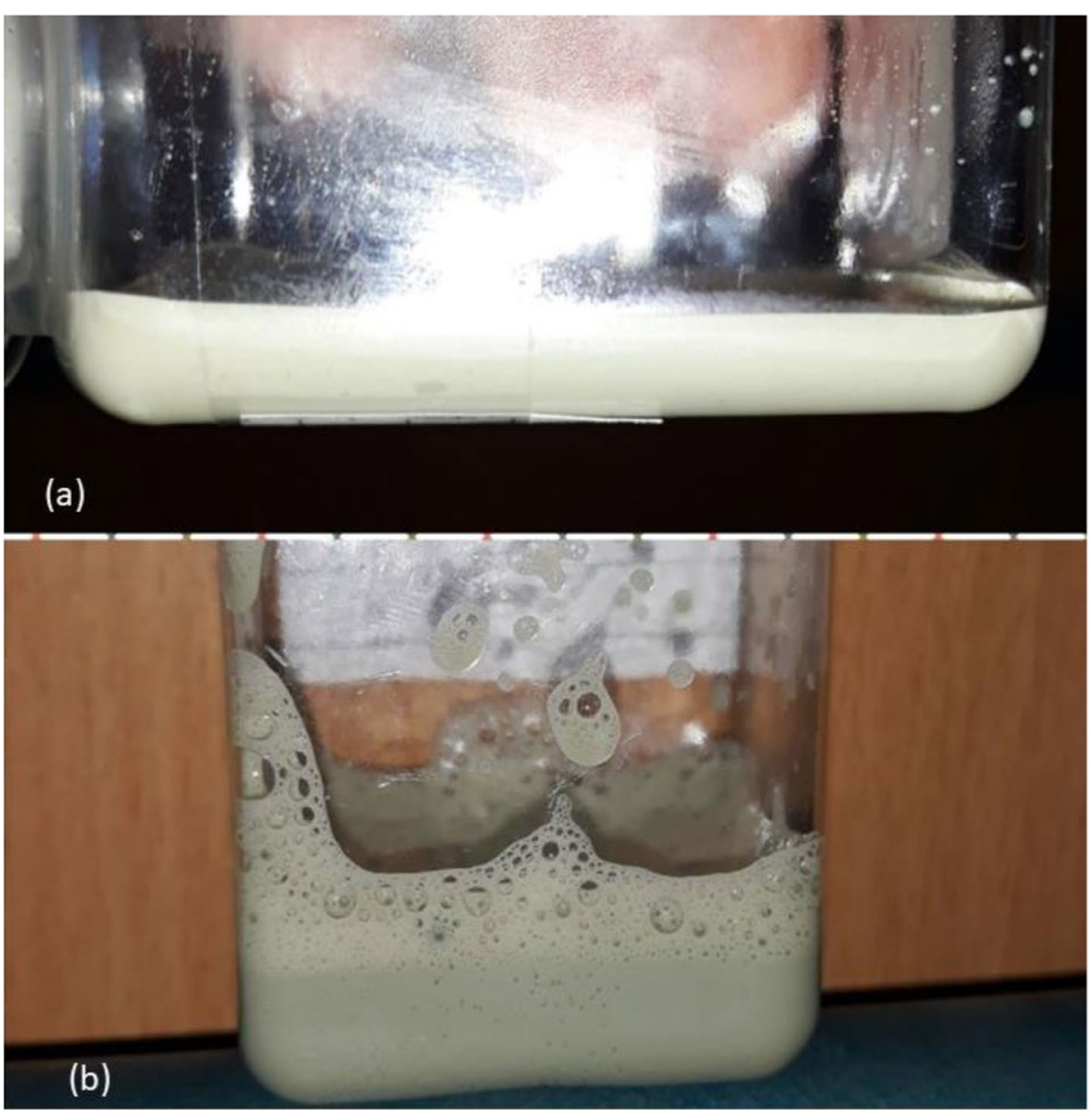

Fig. $4 \mathrm{NN}$ a before and $\mathbf{b}$ after shaking
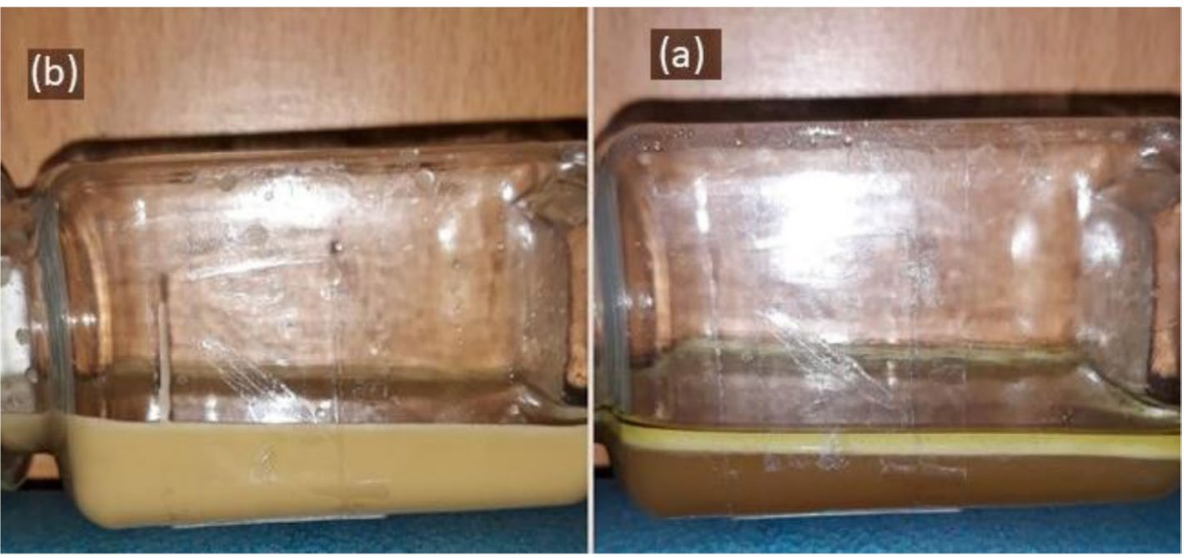

Fig. 5 FN a before and $\mathbf{b}$ after shaking

one day (Fig. 10). The results were suitable and caused a slight cell death suggesting that we could use this amount for further tests.

\section{Antidiabetic tests}

The antidiabetic tests were evaluated by two methods to measure the amount of absorbed glucose and the amount 


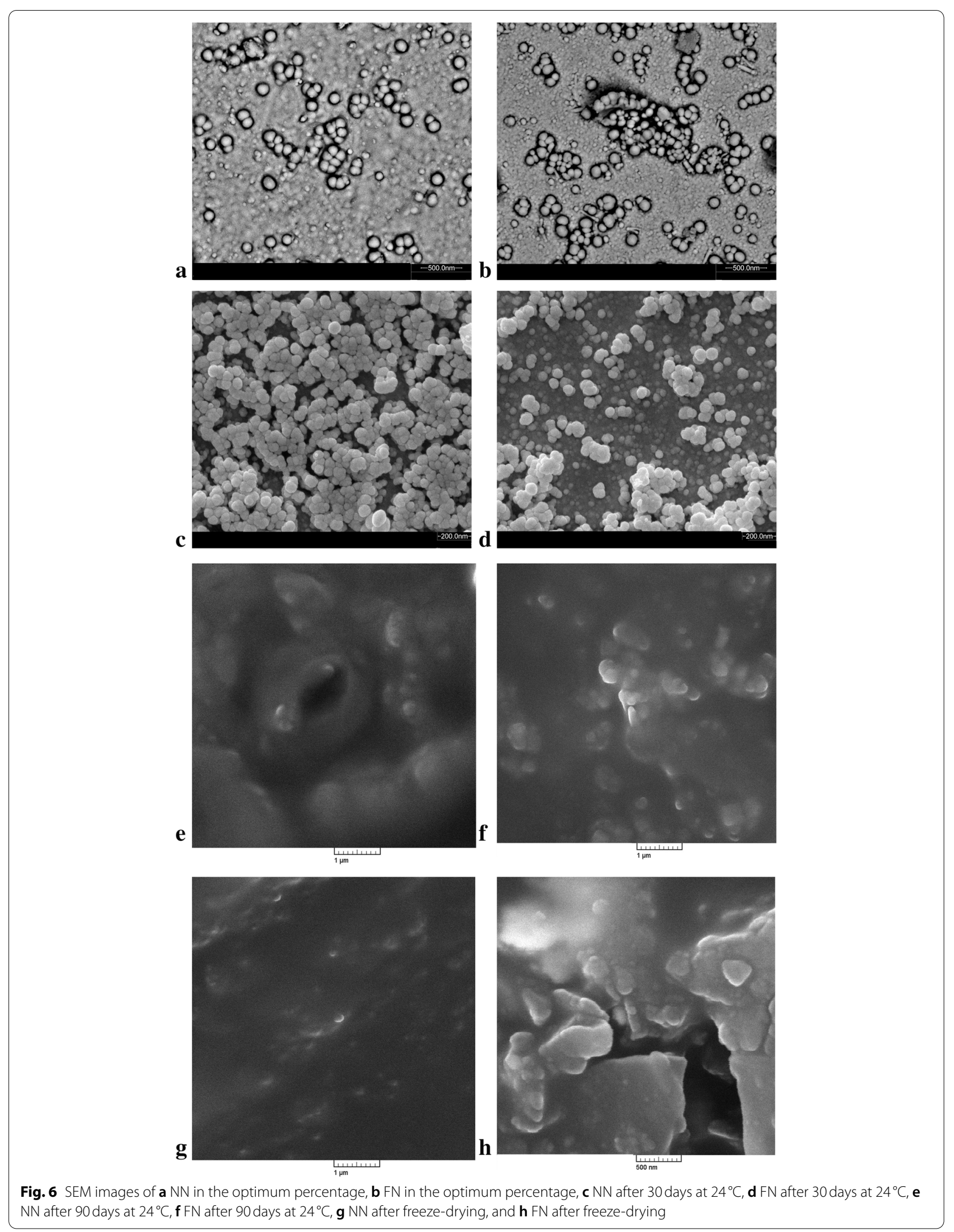



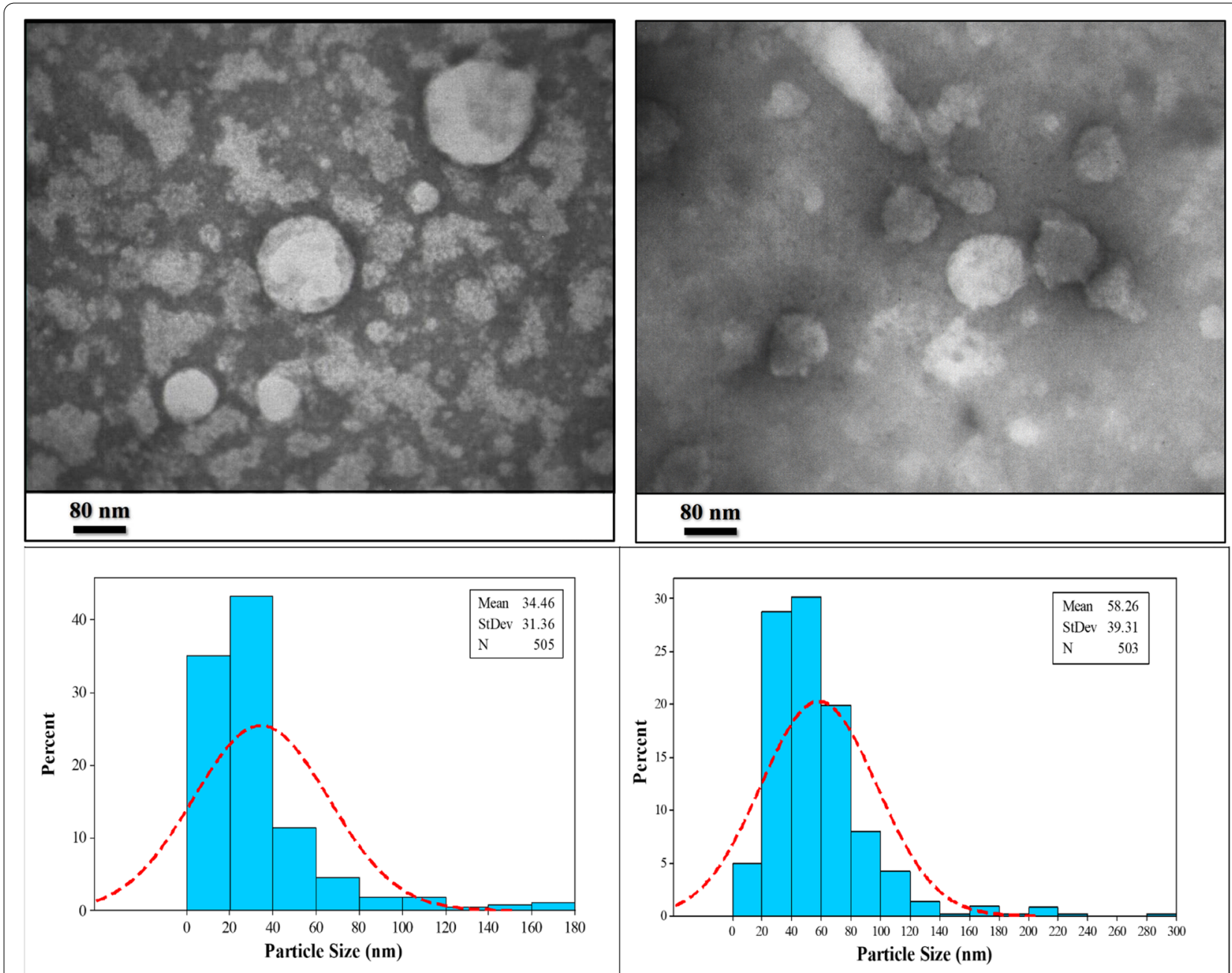

a

Fig. 7 TEM images of $\mathbf{a}$ nettle and $\mathbf{b}$ fenugreek NES

b
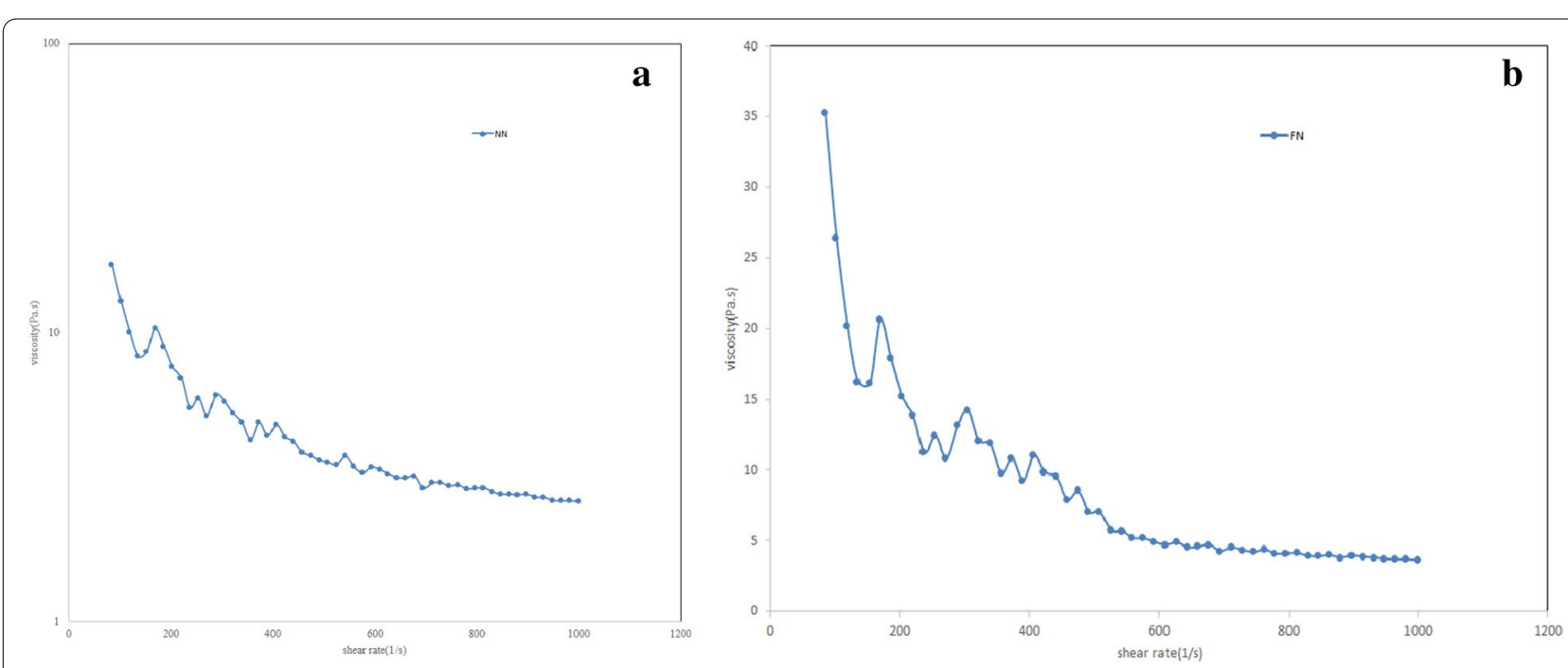

Fig. 8 Viscosity in terms of shear rate of $\mathbf{a}$ nettle and $\mathbf{b}$ fenugreek NEs 
a

1th Day
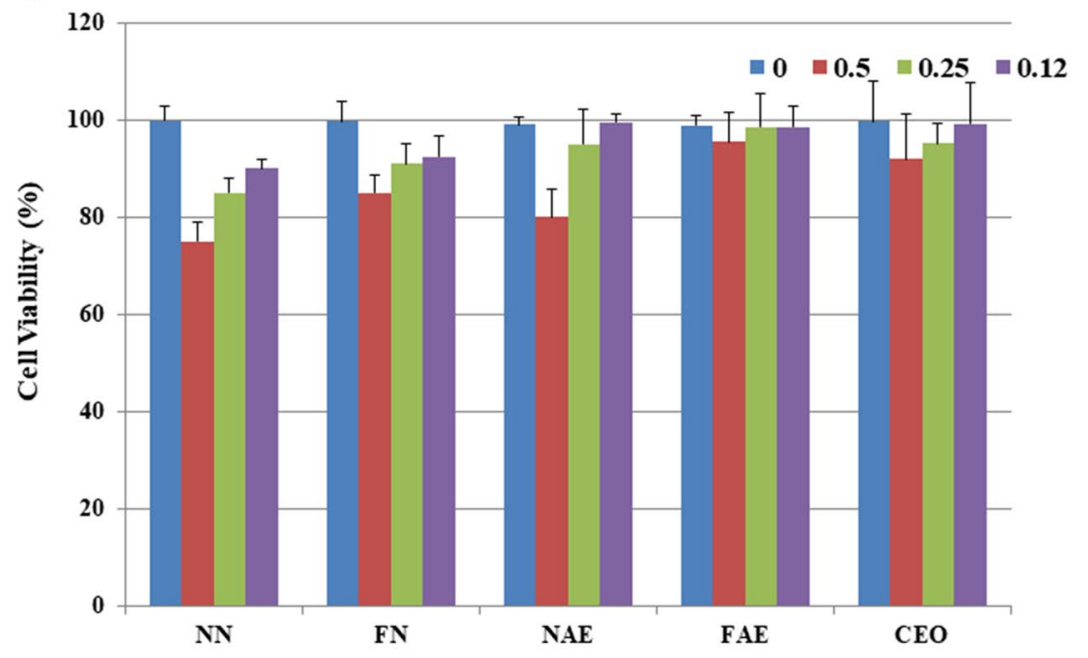

b

3th Day

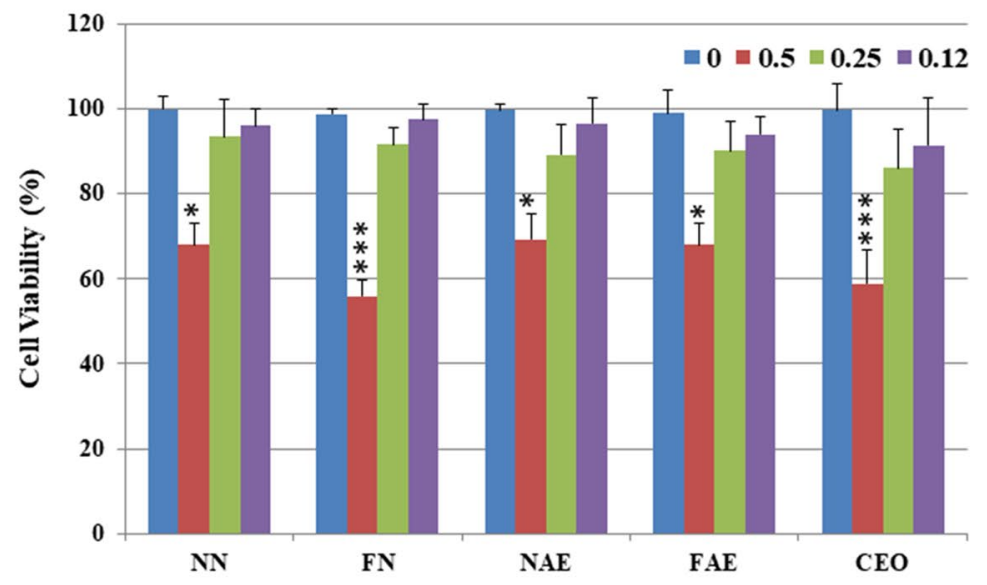

c

5th Day

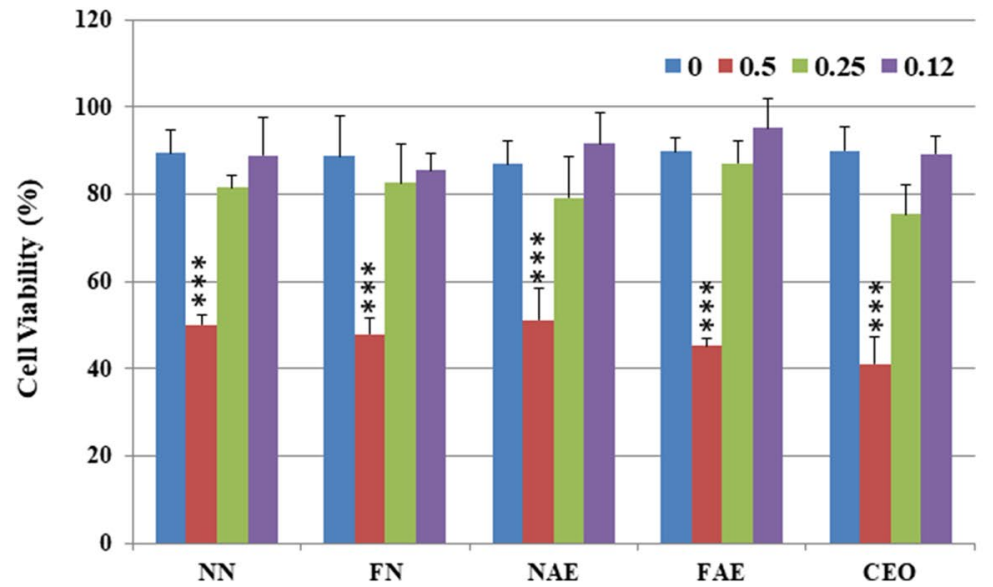

Fig. 9 The cytotoxicity curves of samples in different concentrations for $\mathbf{a} 1$ day, $\mathbf{b} 3$ days, and $\mathbf{c} 5$ days by HEK239 cells 


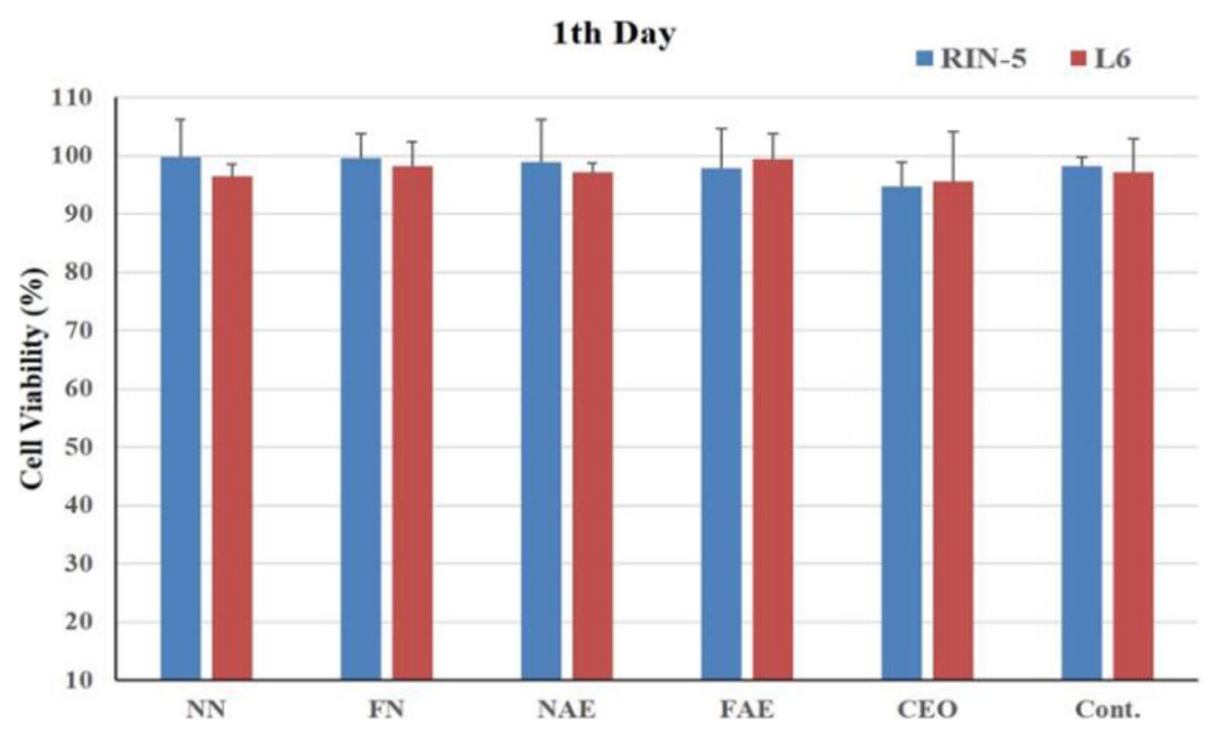

Fig. 10 The cytotoxicity curves of samples in $0.25 \mathrm{mg} / \mathrm{ml}$ for one day by RIN-5 and L6 cells

of released insulin at a concentration of $0.25 \mathrm{mg} / \mathrm{ml}$ of samples. The amount of absorbed glucose was investigated based on average glucose and high glucose by L6 cells with the difference of the entire glucose and the residual glucose in the medium after adding each sample. According to the results of both types of medium, increased glucose absorption was observed after adding FN with raising the glucose levels. Subsequently, CEO showed the highest glucose absorption by the cell. Also, the results were confirmed by the double effect of CEO with the fenugreek extract. According to the results of glucose absorption for each nano-emulsions, the extracts and essential oil were as follows:

In normal glucose:

FN $(50 \mu \mathrm{g} /$ well $)>$ CEO $(46.5 \mu \mathrm{g} /$ well $)>$ FAE $(41.3 \mu \mathrm{g} /$ well $)>\mathrm{NAE}(39.5 \mu \mathrm{g} /$ well $)>\mathrm{NN}(38 \mu \mathrm{g} /$ well $)$

In high glucose:

FN $(96.5 \mu \mathrm{g} /$ well $)>$ CEO $(79.2 \mu \mathrm{g} /$ well $)>\mathrm{NN}(68 \mu \mathrm{g} /$ well $)>$ FAE $(65.2 \mu \mathrm{g} /$ well $)>$ NAE $(59.2 \mu \mathrm{g} /$ well $)$

The glucose absorption was showed by L6 cells for FN, NN, FAE, NAE, and CEO in two media, with normal glucose and high glucose (Fig. 11).

The amount of released insulin was evaluated by RIN-5 cells for all three media, containing high glucose (12.5 mM), low glucose $(6.25 \mathrm{mM})$, and no glucose. Based on the results in both high and low glucose, the level of insulin secretion significantly increased by RIN-5 cells after adding FN to the media, which indicated the excellent effect of this nano-emulsion on the control of diabetes. CEO showed the highest insulin secretion level following FN, which indicated CEO with fenugreek extract increased the control of diabetes. The effect of the
FN and CEO was enhanced with increasing glucose in the medium. According to the results, the order of insulin secretion for each nano-emulsions, the extracts, and essential oil are as follows:

High glucose:

$\mathrm{FN}>\mathrm{CEO}>\mathrm{NN}>\mathrm{FAE}$

Low glucose content:

$\mathrm{FN}>\mathrm{CEO}>\mathrm{NN}>\mathrm{FAE}$

When glucose was not present in the environment, none of the samples had any effect, and insulin levels were normal. The insulin secretion level showed in glucose-free, low glucose, and high glucose levels for FN, NN, NAE, FAE, and CEO (Fig. 12).

In this study, nano-emulsion diminished the blood sugar in vitro confirming the previous reports. The effects of FN and aqueous fenugreek extract confirmed the antidiabetic property in previous studies (Hassan \& Mujtaba, 2017; Al-Habori \& Raman, 1998; Bordia et al., 1997; Kumar et al., 2005; Jaworska et al., 2015; Sauvaire et al., 1998). The effect of CEO confirmed the reduction of blood sugar in previous studies (Samani Keihan et al., 2016; Abdou Mohamed et al., 2018; PatilAmol et al., 2019; Jagtap \& Patil, 2010). The nettle hydroalcoholic extract had a good effect on blood sugar in previous findings (Ahangarpour et al., 2012; Golalipour \& Khori, 2007b). In this research, the NN and NAE did not have a very significant effect on insulin secretion and glucose absorption, showing the influential role of hydroalcoholic extract compared with aqueous extract on antidiabetic properties. The observed effects can be due to the active ingredients in the plants, which have been increased by the preparation of nano-emulsions. 


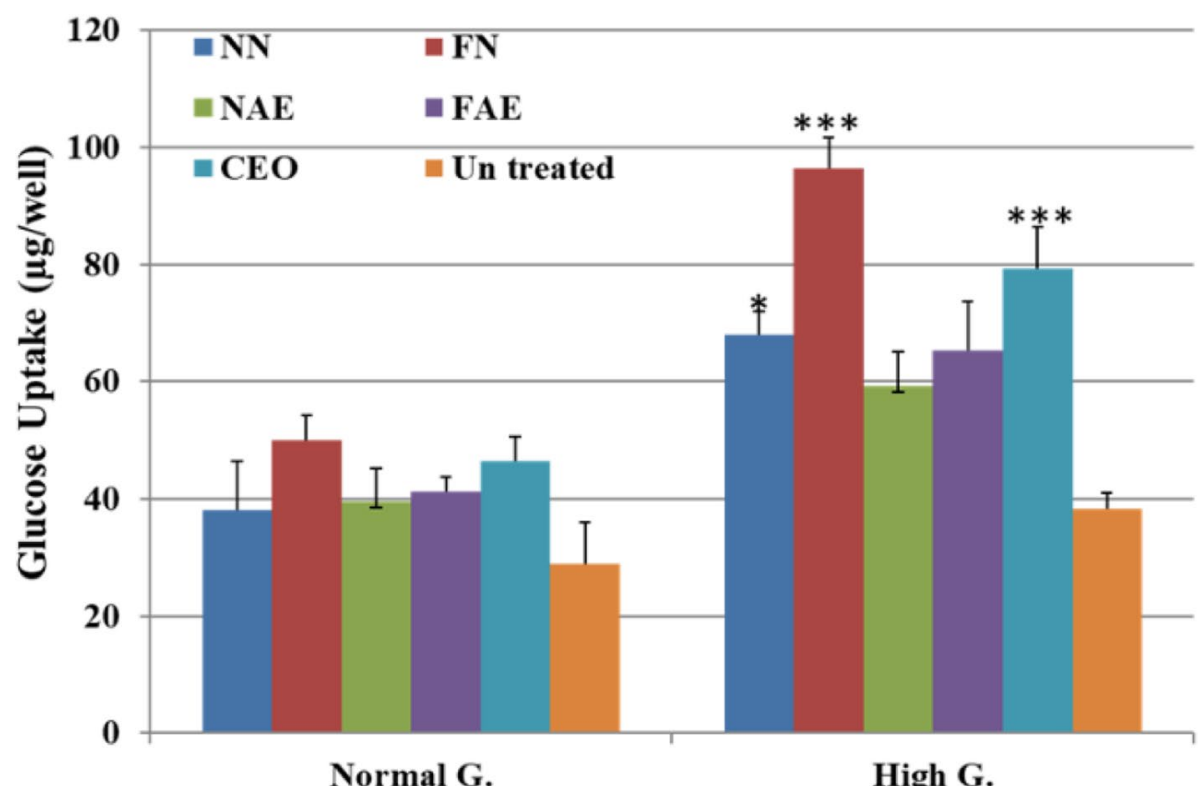

Fig. 11 The glucose absorption of samples in $0.25 \mathrm{mg} / \mathrm{ml}$ for one day by RIN-5 and L6 cells

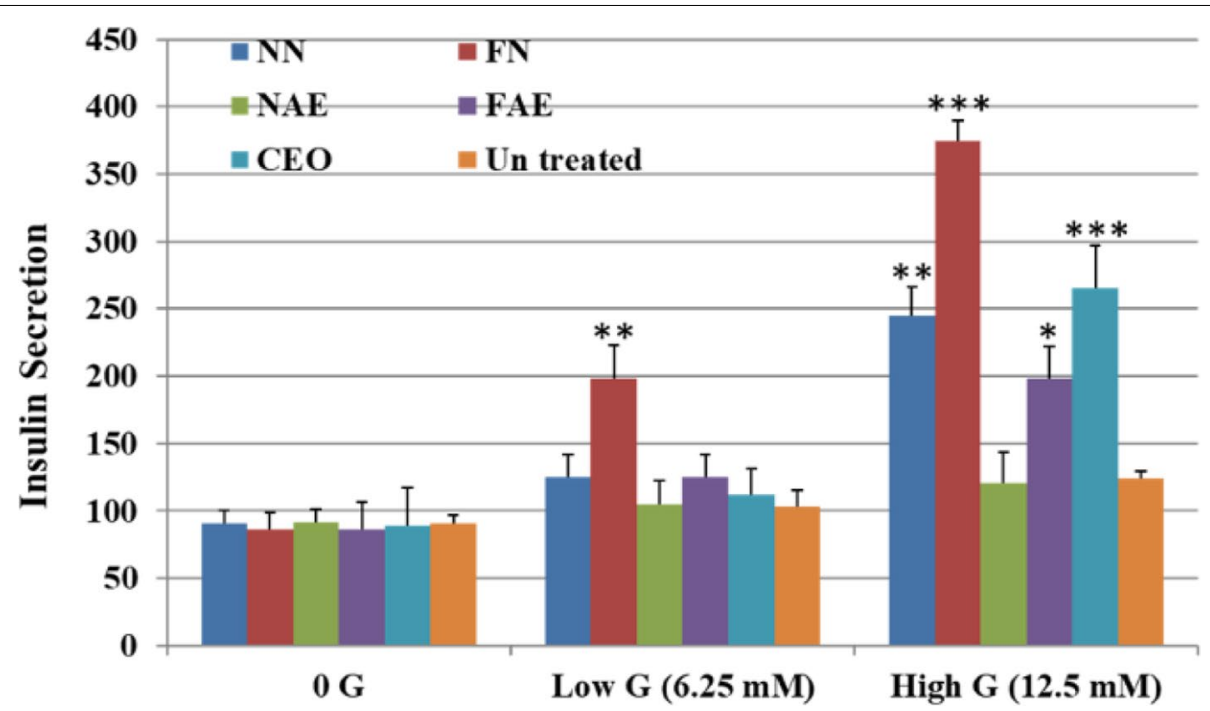

Fig. 12 The insulin secretion level by RIN-5 cell culture in glucose-free, low glucose, and high glucose levels for samples

\section{Conclusion}

This study demonstrated a nano-emulsion based on the plants with a simple and cost-effective method. The optimum sample contained NAE $(95 \% \mathrm{w} / \mathrm{w})$, tween $80(1 \%$ $\mathrm{w} / \mathrm{w})$, and CEO (4\% w/w) for NN and FAE ( $95 \% \mathrm{w} / \mathrm{w})$, span $80(1 \% \mathrm{w} / \mathrm{w})$, and CEO $(4 \% \mathrm{w} / \mathrm{w})$ for FN with low cytotoxicity for HEK239, RIN-5, and L6 cells. DLS and SEM results revealed a single peak with a narrow distribution diagram and nanoparticles with spherical morphology, respectively. According to TEM results, the particle size was observed $58.3 \mathrm{~nm}$ for FN and $34.5 \mathrm{~nm}$ for NN. Based on DLS and SEM analyses, samples had good and suitable stability after different times (30 and 90 days), temperatures $\left(24,4,-4\right.$, and $\left.-20^{\circ} \mathrm{C}\right)$, and freeze-drying. Given the advantages of $\mathrm{FN}$, it can be a good candidate for diabetes control and treatment as a pharmaceutical and food agent with low toxicity than chemical drugs in the future. 


\section{Abbreviations}

Cumin: Cuminum cyminum; CEO: Cumin essential oil; DLS: Dynamic light scattering; Fenugreek: Trigonella foenum-graecum; FE: Fenugreek extract; FAE: Fenugreek aqueous extract; FN: Fenugreek nano-emulsions; FBS: Fetal bovine serum; HEK293: Human embryonic kidney cells; NE: Nano-emulsion; NPs: Nanoparticles; Urtica dioica: Nettle; NE: Nettle extract; NAE: Nettle aqueous extract; NN: Nettle nano-emulsion; O/W: Oil-in-water; O/W/O: Oil in water in oil; PBS: Phosphate buffer solution; L6: Rat L6 myoblast cell line; RIN-5: Mouse pancreatic beta-cell; SEM: Scanning electron microscopy; SLNs: Solid lipid nanoparticles; TEM: Transmission electron microscopy; W/O: Water-in-oil; W/O/W: Water in oil in water.

\section{Acknowledgements}

\section{Not applicable.}

\section{Authors' contributions}

Ms. Sara Javadi is a student and Dr. Motakef-Kazemi is supervisor and Raheleh Halabian is an adviser. The authors read and approved the final manuscript.

\section{Funding}

We did not receive any funding for this research.

\section{Availability of data and materials}

We agree to make the data and materials available.

\section{Declarations}

\section{Competing interests}

The authors declare that they have no competing interests.

\section{Author details}

${ }^{1}$ Department of Nanochemistry, Faculty of Pharmaceutical Chemistry, Tehran Medical Sciences, Islamic Azad University, Tehran, Iran. ${ }^{2}$ Department of Medical Nanotechnology, Faculty of Advanced Sciences and Technology, Tehran Medical Sciences, Islamic Azad University, Tehran, Iran. ${ }^{3}$ Applied Microbiology Research Center, Systems Biology and Poisonings Institute, Baqiyatallah University of Medical Sciences, Tehran, Iran.

\section{Received: 19 June 2021 Accepted: 23 November 2021}

Published online: 28 December 2021

\section{References}

Abdelatif AM, Ibrahim MY, Mahmoud AS (2012) Antidiabetic effects of fenugreek (Trigonella foenum-graecum) seeds in the domestic rabbit (oryctolagus cuniculus). J Med Plant Res 6(6):449-455

Abdou Mohamed D, Hamed IM, Aly FK (2018) Antioxidant and antidiabetic effects of cumin seeds crude ethanol extract. J Biol Sci 18(5):251-259

Ahangarpour A, Mohammadian M, Dianat M (2012) Antidiabetic effect of hydroalcholic urtica dioica leaf extract in male rats with fructose-induced insulin resistance. Iran J Med Sci 37(3):181-186

Al-Habori A, Raman A (1998) Antidiabetic and hypocholesterolaemic effects of fenugreek. Phytother Res 12:233-242

Al-Habori M, Raman A (1985) Antidiabetic and hypocholesterolaemic effects of fenugreek seeds. Planta Med 51:533-534

Ataei F, Dorranian D, Motakef KN (2020) Bismuth-based metal-organic framework prepared by pulsed laser ablation method in liquid. J Theor Appl Phys 14:1-8

Azrini Nadiha Azmi N, Elgharbawy AAM, Rezaei Motlagh S, Samsudin N, Salleh HM (2019) Nano-emulsions: factory for food, pharmaceuticaland cosmetics. Processes 7:617

Bahmani M, Shirzad HA, Majlesi M, Shahinfard N, Rafieian-Kopaei M (2014) A review study on analgesic applications of Iranian medicinal plants. Asian Pac J Trop Med 7(1):43-53

Barnes J, Anderson LA, Phillipson JD (1996) Herbal medicines: a guide for healthcare professionals. Pharmaceutical Press, pp 117-118 248

Basch E, Ulbricht C, Kuo G, Szapary P, Smith M (2003) Therapeutic applications of fenugreek. Altern Med Rev 8(1):20-27
Bathaie S, Mokarizade N, Shirali S (2012) An overview of the mechanisms of plant ingredients in the treatment of diabetes mellitus. J Med Plant 4(44):1-24

Bettaieb I, Knioua S, Hamrouni I, Limam F, Marzouk B (2011) Water-deficit impact on fatty acid and essential oil composition and antioxidant activities of cumin (cuminum cyminum L.) aerial parts. J Agric Food Chem 59(1):328-334

Bordia A, Verma SK, Serivastava KC (1997) Effect of ginger (Zingiber of officinal rose) and fenugreek on blood lipid, blood sugar and palatlete aggregation in patients with coronary artry disease. Prostaglandins Leukot Essent Fat Acids 56(5):379-384

Bouchemal K, Briancon S, Perrier E, Fessi H (2004) Nano-emulsion formulation using spontaneous emulsification: solvent, oil and surfactant optimisation. Int J Pharm 280:241-251

Dehghani F, Farhadian N, Golmohammadzadeh S, Biriaee A, Ebrahimi M, Karimi M (2017) Preparation, characterization and in-vivo evaluation of microemulsions containing tamoxifen citrate anti-cancer drug. Eur J Pharm Sci 96:479-489

Deli G, Hatziantoniou S, Nikas Y, Demetzos C (2009) Solid lipid nanoparticles and nano-emulsions containing ceramides: preparation and physicochemical characterization. J Liposome Res 19(3):180-188

Dey L, Attele AS, Yuan CS (2002) Alternative therapies for type 2 diabetes. Altern Med Rev 7:45-58

Duke JA (2002) Handbook of medicinal herbs. CRC Press, p 490

Feizi Langaroudi N, Motakef KN (2019) Preparation and characterization of O/W nano-emulsion with mint essential oil and parsley aqueous extract and the presence effect of chitosan. Nanomed Res J 4(1):48-55

Ghalavand A, Motamedi P, Deleramnasab M, Khodadoust M (2017) The effect of interval training and nettle supplement on glycemic control and blood pressure in men with type 2 diabetes. Int J Basic Sci Med 2(1):33-40

Golalipour M, Khori V, Ghafari S, Mohammad Gharravi A (2006) Chronic effect of the hydroalcholic extract of Urtica dioica leaves on regeneration of Bcells of hyperglycemic rats. Pak J Biol Sci 9:1482-1485

Golalipour MJ, Khori V (2007a) The protective activity of Urtica dioica leaves on blood glucose concentration and $\beta$-cell in Streptozotocin-diabetic rats. Pak J Biol Sci 8:1200-1204

Golalipour MJ, Khori V (2007b) The protective effect of the hydroalcholic extract of urtica dioica leaves on blood glucose concentration and $\beta$-cells in hyperglycemic rats. BUMS. 9(1):7-13

Gomez-Perez FJ, Aguilar-Salinas CA, AlmedaValdes P, Cuevas-Ramos D, Lerman Garber I, Rull JA (2010) HbA1c for the diagnosis of diabetes mellitus in a developing country. Arch Med Res 4:302-328

Hajiashrafi S, Motakef KN (2018) Green synthesis of zinc oxide nanoparticles using parsley extract. Nanomed Res J 3(1):44-50

Hasani-Ranjbar SH, Mohammad Abdollahi BL (2008) A systematic review of Iranian medicinal plants useful in diabetes mellitus. World J Gastroenterol 15(25):3073-3085

Hassan KAM, Mujtaba MA (2017) Oral nano-emulsion of fenugreek oil for treatment of diabetes. Int J Pharm Sci Res 8(7):3151-3154

Haziqah Che Marzuki N, Abdul Wahab R, Abdul Hamid M (2019) An overview of nano-emulsion: concepts of development and cosmeceutical applications. Biotechnol Biotechnol Equip 33(1):779-797

Hirono T, Homma M, Oka K (1994) Effects of stinging nettle root extracts and their steroidal components on the $\mathrm{Na}$, $\mathrm{K}$ : ATPase of the benign prostatic hyperplasia. Planta Med 60(1):30-33

Hormann K, Zimmer A (2016) Drug delivery and drug targeting with parenteral lipid nano-emulsions- a review. J Control Release 223:85-98

Hu XB, Tang TT, Li YJ, Wu JY, Wang JM, Liu XY, Xiang DX (2019) Phospholipid complex based nano-emulsion system for oral insulin delivery: preparation, in vitro, and in vivo evaluations. Int J Nanomedicine 14:3055-3067

Hussein J, El-Bana M, Refaat E, El-Naggar ME (2017) Synthesis of carvacrolbased nano-emulsion for treating neurodegenerative disorders in experimental diabetes. J Funct Foods 37:441-448

Jafari S, Sattari R, Ghavamzadeh S (2017) Evaluation the effect of 50 and 100 mg doses of cuminum cyminum essential oil on glycemic indices, insulin resistance and serum inflammatory factors on patients with diabetes type II: a double-blind randomized placebo-controlled clinical trial. J Tradit Complement Med 7(3):332-338

Jagtap A, Patil P (2010) Antihyperglycemic activity and inhibition of advanced glycation end product formation by cuminum cyminum in streptozotocin induced diabetic rats. Food Chem Toxicol 48(8-9):2030-2036 
Jaworska M, Sikora E, Ogonowski J (2015) Rheological properties of nanoemulsions stabilized by polysorbate 80. Chem Eng Technol 38(8):1469-1476

Jeevanandam J, Barhoum A, Chan YS, Dufresne A, Danquah MK (2018) Review on nanoparticles and nanostructured materials: history, sources, toxicity and regulations. Beilstein J Nanotechnol 9:1050-1074

Kaltsa O, Spiliopoulou N, Yanniotis S, Mandala I (2016) Stability and physical properties of model macro-and nano/submicron emulsions containing fenugreek gum. Food Hydrocoll 61:625-632

Kamalakkannan N, Prince PS (2006) Antihyperglycaemic and antioxidant effect of rutin, a polyphenolic flavonoid, in streptozotocin-induced diabetic wistar rats. Basic Clin Pharmacol Toxicol 98:97-103

Karimi E, Motakef KN (2021) Preparation of O/W nanoemulsion containing saffron aqueous solution and sesame oil and evaluation of its properties. Nanomed Res J 6(2):112-116

Kazi S (2014) Use of traditional plants in diabetes mellitus. Int J Pharm 4(4):283-289

Kooti W, Moradi M, Akbari SA, Sharafi-Ahvazi N, AsadiSamani M, Ashtary-Larky D (2015) Therapeutic and pharmacological potential of Foeniculum vulgare mill: a review. J HerbMed Pharmacol 4:1-9

Kregie D, Pawlikowska E, Antolak H (2018) Urtica spp: ordinary plants with extraordinary properties. Molecules. 23(7):E1664

Kumar M, Singh Bishnoi R, Kumar Shukla A, Prakash JC (2019) Techniques for formulation of nano-emulsion drug delivery system: a review. Prev Nutr Food Sci 24(3):225-234

Kumar SG, Shetty AK, Sambaiah K, Salimath PV (2005) Antidiabetic property of fenugreek seed mucilage and spent turmeric in streptozotocin-induced diabetic rats. Nutr Res 25(11):1021-1028

Kumari S, Kumaraswamy RV, Chandra Choudhary R, Sharma SS, Pal A, Raliya R, Biswas P, Saharan V (2018) Thymol nano-emulsion exhibits potential antibacterial activity against bacterial pustule disease and growth promotory effect on soybean. Sci Rep 8:6650

Laligani B, Abolhasani F, Mohajeri Tehrani MR, Tabatabaei O (2005) Prevalence of diabetes mellitus in Iran in 2000. Iranian J Diabetes lipid Disor 4(3):75-83

Landon MB, Spong CY, Thom E, Carpenter MW, Ramin SM, Casey B, Wapner RJ, Varner MW, Rouse DJ, Thorp JM, Sciscione A, Catalano P, Harper M, Saade G, Lain KY, Sorokin Y, Peaceman AM, Tolosa JE, Anderson GB (2009) Eunice kennedy shriver national institute of child health and human development maternal fetal medicine units' network, a multicenter, randomized trial of treatment for mild gestational diabetes. N Engl J Med 361:1339-1348

Lee HS (2005a) Cuminaldehyde: aldose reductase and alpha-glucosidase inhibitor derived from Cuminum cyminum L. seeds. J Agric Food Chem 53(7):2446-2450

Lee HS (2005b) Cuminaldehyde: aldose reductase and a-glucosidase inhibitor derived from cuminum cyminum L. seeds. J Agric Food Chem 53:2446-2450

Leung AY, Foster S (1996) Encyclopedia of common natural ingredients: used in food, drugs, and cosmetics. Wiley. 64:82

Madar Z, Shomer I (1990) Polysacharide composition of a gel fraction derived from fenugreek and its effect on starch digestion and bile acid absorbtion in rats. J Agric Food Chem 38:1535-1539

Mc Clements DJ (2013) Nano emulsion-based oral delivery systems for lipophilic bioactive components: nutraceuticals and pharmaceuticals. Ther Deliv 4(7):841-857

Mehri A, Larijani B, Abdollahi M (2011) A systematic review of efficacy and safety of Urtica dioica in the treatment of diabetes. Int J Pharmacol 7:161-170

Mehrnia MA, Jafari SM, Makhmal-Zadeh BS, Maghsoudlou Y (2017) Rheologica and release properties of double nano-emulsions containing crocin prepared with Angum gum, Arabic gum and whey protein. Food Hydrocoll 66:259-267

Modak M, Dixit P, Londhe J, Ghaskadbi S, Devasagayam TPA (2007) Indian herbs and herbal drugs used for the treatment of diabetes. J Clin Biochem Nutr 40(3):163-173

Motakef Kazemi N, Rashidian M, Taghizadeh Dabbagh S, Masoumeh YM (2020) Synthesis and characterization of bismuth oxide nanoparticles by thermal decomposition of bismuth-based MOF and evaluation of its nanocomposite. https://doi.org/10.30492/ijcce.2019.37263

Motakef Kazemi N, Sandalnia M (2020) In situ production and deposition of bismuth oxide nanoparticles on cotton fabric. ISTT. 44:1217-1223
Mowla A, Alauddin M, Rahman MA, Ahmed K (2009) Antihyperglycemic effect of Trigonella foenum-graecum (fenugreek) seed extract in alloxan-induced diabetic rats and its use in diabetes mellitus: a brief qualitative phytochemical and acute toxicity test on the extract. Afr J Tradit Complement Altern Med 6(3):255-261

Mukesh R, Namita P (2013) Medicinal plants with antidiabetic potential-a review. Am Eurasian J Agric Environ Sci 13(1):81-94

Najafi-taher R, Ghaemi B, Kharazi S, Rasoulikoohi S, Amani A (2018) Promising antibacterial effects of silver nanoparticle-loaded tea tree oil nanoemulsion: a synergistic combination against resistance threat. AAPS PharmSCiTech 19(3):1133-1140

Neelakantan N, Narayanan M, de Souza RJ, van Dam RM (2014) Effect of fenugreek (Trigonella foenum-graecum L.) intake on glycemia: a meta-analysis of clinical trials. Nutr J 13(7):1-11

Obertreis B, Giller K, Teucher T, Behnke B, Schmitz H (1990) Anti-inflammatory effect of Urtica dioica folia extract in comparison to caffeic malic acid. Arzneim Forsch 46(1):52-56

PatilAmol SC, Tagalpallewar A, Kokare CR (2019) Natural anti-proliferative agent loaded self-microemulsifying nanoparticles for potential therapy in oral squamous carcinoma. J Pharm Investig 49(5):527-541

Pickup JC, Zhi ZL, Khan F, SaxI T, Birch DJS (2008) Nanomedicine and its potential in diabetes research and practice. Diabetes Metab 28(8):604-610

Rahimzadeh M, Jahanshahi S, Moein S, Moein MR (2014) Evaluation of alphaamylase inhibition by Urtica dioica and Juglans regia extracts. Iran J Basic Med Sci 17:465-469

Rehana D, Mahendiran D, Kumar RS, Rahiman AK (2017) In vitro antioxidant and antidiabetic activities of zinc oxide nanoparticles synthesized using different plant extracts. Bioprocess Biosyst Eng 40(6):943-957

Saki K, Bahmani M, Rafieian-Kopaei M (2014) The effect of most important medicinal plants on two important psychiatric disorders (anxiety and depression)-a review. Asian Pac J Trop Med 7(1):34-42

Samani Keihan G, Ghari MH, Momeni A, Hemati Z, Sedighin R (2016) A comparison between the effect of Cuminum Cyminum and vitamin $\mathrm{E}$ on the level of leptin, paraoxonase $1, \mathrm{HbA} 1 \mathrm{c}$ and oxidized LDL in diabetic patients. Int J Mol Cell Med 5(4):229-235

Saratale RG, Shin HS, Kumar G, Benelli G, Kim DS, Saratale GD (2018) Exploiting antidiabetic activity of silver nanoparticles synthesized using Punica granatum leaves and anticancer potential against human liver cancer cells (HepG2). Artif Cells Nanomed Biotechnol 46(1):211-222

Sauvaire Y, Petit P, Broca C (1998) 4-Hydroxyisoleucine: a novel amino acid potentiator of insulin secretion. Diabetes. 47:206-210

Saxena A, Vikram NK (2004) Role of selected Indian plants in management of type 2 diabetes: a review. J Altern Complement Med 10:369-378

Sharifi F, Jahangiri M, Nazir I, Hussain Asim M, Ebrahimnejad P, Hupfauf A, Gust R, Bernkop-Schnürch A (2021) Zeta potential changing nanoemulsions based on a simple zwitterion. J Colloid Interface Sci 585:126-137

Si S, Pal A, Mohanta J, Satapathy S (2017) Gold nanostructure materials in diabetes management. J Phys D 50(13):1-46

Silva HD, Cerqueira MÂ, Vicente AA (2012) Nano-emulsions for food applications: development and characterization. Food Bioprocess Technol 5:854-867

Singh R, Dar SA, Sharma P (2012) Antibacterial activity and toxicological evaluation of semipurified hexane extract of Urtica dioica leaves. Res I Med Plants 6:123-135

Song Y, Manson JE, Buring JE, Sesso HD, Liu S (2005) Associations of dietary flavonoids with risk of type 2 diabetes, and markers of insulin resistance and systemic inflammation in women: a prospective study and crosssectional analysis. J Am Coll Nutr 24:376-384

Srinivasan K (2018) Cumin (Cuminum cyminum) and black cumin (Nigella sativa) seeds: traditional uses, chemical constituents, and nutraceutical effects. J Food Saf Food Qual 2(1):1-16

Talpur N, Echard B, Ingram C, Bagchi D, Preuss H (2005) Effects of a novel formulation of essential oils on glucose-insulin metabolism in diabetic and hypertensive rats: a pilot study. Diab Obes Metab 7(2):193-199

Tan SF, Masoumi HR, Karjiban RA, Stanslas J, Kirby BP, Basri M, Bin BH (2016) Ultrasonic emulsification of parenteral valproic acid-loaded nano-emulsion with response surface methodology and evaluation of its stability. Ultrason Sonochem 29:299-308

Tarighat Esfanjani A, Namazi N, Bahrami A, Ehteshami M (2012) Effect of hydroalcoholic extract of nettle (Urtica dioica) on glycemic index and insulin resistance index in type 2 diabetic patients. Iran J Endocrinol Metab 13(6):561-568 
Teucher T, Obertreis B, Ruttkowski T, Schmitz H (1996) Cytokine secretion in whole blood of healthy subjects following oral administration of Urtica dioica L. plant extract. Arzneimittelforschung 46:906-910

Wang E, Wylie-Rosett J (2008) Review of selected Chinese herbal medicines in the treatment of type 2 diabetes. Diabetes Educ 34:645-654

Wang J, Shi A, Agyei D, Wang Q (2017) Formulation of water-in-oil-inwater (W/O/W) emulsions containing trans-resveratrol. R Soc Chem 7:35917-35927

Wichtl M, Bisset NG (1994) Herbal drugs and phytopharmaceuticals: a handbook for practice on a scientific basis. Medpharm Scientific Publishers:203-205

Zeinali M, Abbaspour-Ravasjani S, Ghorbani M, Babazadeh A, Soltanfam T, CláudiaSantos A, Hamishehkar H, Hamblin MR (2020) Nanovehicles for co-delivery of anti cancer agents. Drug Des Discov 25(8):1416-1430

\section{Publisher's Note}

Springer Nature remains neutral with regard to jurisdictional claims in published maps and institutional affiliations.

\section{Submit your manuscript to a SpringerOpen ${ }^{\circ}$ journal and benefit from:}

- Convenient online submission

- Rigorous peer review

- Open access: articles freely available online

- High visibility within the field

- Retaining the copyright to your article

Submit your next manuscript at $\boldsymbol{\nabla}$ springeropen.com 